Marquette University

e-Publications@Marquette

Biomedical Engineering Faculty Research and

Publications

Biomedical Engineering, Department of

$12-31-2006$

Upper Extremity Dynamics During Lofstrand Crutch-Assisted Gait in Children With Myelomeningocele

Brooke A. Slavens

Marquette University, brooke.slavens@marquette.edu

Jamie Frantz

Medical College of Wisconsin

Peter F. Sturm

Shriners Hospitals for Children

Gerald F. Harris

Marquette University, gerald.harris@marquette.edu

Accepted version. The Journal of Spinal Cord Medicine, Vol. 30, No. Suppl. 1 (2007): S165-S171.

Permalink. (C) 2007 Maney Publishing. Used with permission. 


\title{
Upper Extremity Dynamics During Lofstrand Crutch-Assisted Gait in Children With Myelomeningocele
}

\author{
Brooke A. Slavens \\ Department of Biomedical Engineering, Marquette University \\ Orthopaedic and Rehabilitation Engineering Center \\ Milwaukee, WI \\ Jamie Frantz \\ Medical College of Wisconsin \\ Milwaukee, WI \\ Peter F. Sturm \\ Shriners Hospitals for Children \\ Chicago, IL \\ Gerald F. Harris \\ Department of Biomedical Engineering, Marquette University, \\ Orthopaedic and Rehabilitation Engineering Center \\ Medical College of Wisconsin \\ Milwaukee, WI \\ ${ }^{4}$ Shriners Hospitals for Children \\ Chicago, IL
}


NOT THE PUBLISHED VERSION; this is the author's final, peer-reviewed manuscript. The published version may be accessed by following the link in the citation at the bottom of the page.

\section{Abstract}

\section{Background/Objective:}

We present a 3-dimensional biomechanical model of the upper extremities to characterize joint dynamics during 2 patterns of Lofstrand crutch-assisted gait in children with myelomeningocele. The upper extremity model incorporates recommendations by the International Society of Biomechanics.

\section{Methods:}

A Vicon motion analysis system (14 cameras) captured the marker patterns. Instrumented crutches measured reaction forces. Five subjects with L3 or L4 level myelodysplasia (aged $9.8 \pm 1.6$ years) were analyzed during reciprocal and swing-through Lofstrand crutch-assisted gait.

\section{Results:}

The mean walking speed, cadence, and stride length were greatest during swing-through gait. Although the gait patterns had different morphologies, the thorax and elbows remained in flexion, the wrists remained in extension, and the shoulders demonstrated both flexion and extension throughout the gait cycles. Swing-through gait showed larger ranges of motion for all joints than reciprocal gait. Peak crutch forces were highest during swing-through gait. The model was effective in detecting significant differences in upper extremity joint dynamics between reciprocal and swing-through crutchassisted gait in children with myelomeningocele.

\section{Conclusions:}

Results support continued testing. Future work should include clinical and functional assessment in a correlated study of dynamics and function. Knowledge from the study may be useful in treatment planning and intervention.

Keywords: Crutch-assisted gait, Myelomeningocele, Motion analysis, Upper extremity modeling, Biomechanics

The Journal of Spinal Cord Medicine, Vol. 30, Supplement 1 (2007): pg. S165-S171. Publisher Link. This article is (C) Maney Publishing and permission has been granted for this version to appear in e-Publications@ Marquette. Maney Publishing does not grant permission for this article to be further copied/distributed or hosted elsewhere without the express permission from Maney Publishing. 
NOT THE PUBLISHED VERSION; this is the author's final, peer-reviewed manuscript. The published version may be accessed by following the link in the citation at the bottom of the page.

\section{INTRODUCTION}

Myelomeningocele (MM) is the most common central nervous system birth defect in the United States (1). It is defined as the failure of the neural tube to close, resulting in a cystic dilatation of meninges and protuberance of the spinal cord through the vertebral defect ( $\underline{2})$. In the United States, approximately 1,340 infants are born with MM each year ( $\underline{3})$. Birth incidence of the disease was reported to be 3.68 cases per 10,000 live births from 1999 to 2001 (4). Patients with MM present with a multitude of impairments, but the primary functional deficits are lower limb paralysis and sensory loss (므). The etiology in most cases of MM is multifactorial, involving genetic, racial, and environmental factors. Due to increased survival of individuals with myelomeningocele, it is important that the disease be better understood in order to improve treatment and rehabilitation procedures ( $\underline{1})$.

Myelomeningocele is a complex disease that often results in functional disability. The low-lumbar group (L3-L4 level) retains movement of hip flexor, adductor, medial hamstring, and quadriceps muscles, but strength of the lateral hamstrings, hip abductors, and ankle dorsiflexors is variable ( $\underline{5})$. Ambulatory ability is closely related to quadriceps function ( $\underline{6})$. Studies have shown that approximately 50 to $60 \%$ of young adult patients ambulate in the household or community, with approximately $20 \%$ of these patients using some orthotic or assistive device (모). Due to the large number of children with MM who are dependent on crutches, we are interested in characterizing the motion and forces that occur during Lofstrand crutch-assisted ambulation. The information gained from this study may aid crutch prescription and therapeutic planning.

Kinematics and kinetics of the lower extremity during crutchassisted gait have been studied extensively in children with MM using 3-dimensional (3D) motion analysis (7-11). However, movements of the upper extremity (UE) (ie, thorax, shoulder, elbow, and wrist) during walking have only been investigated to a small extent in children with MM (12-14). Work by Moore et al confirms the need for UE dynamic analysis of crutch-assisted gait in children with MM (15). Previous studies on the dynamics of crutch-assisted gait have been 
limited by the kinematic model and/or small population sizes $(\underline{16}, \underline{17})$. The few existing UE dynamic models lack 3D joint angle calculations (12) or were not developed for a pediatric MM population (16-20). A study by Requejo et al reported UE kinematics and kinetics of reciprocal crutch-assisted gait of one patient with spinal cord injury (17). Limitations include the nonstandardized model and small sample population. Currently, data for 3D UE dynamics during crutch-assisted gait have not been reported for children with MM.

In order to quantify crutch-assisted gait, an effective dynamic model must be applied. Most UE kinematic models do not incorporate the standards suggested by the Standardization and Terminology Committee of the International Society of Biomechanics (ISB) (21). This group proposed definitions of a joint coordinate system for the shoulder, elbow, and wrist. The adoption of these standards is encouraged for better communication among researchers and clinicians. For this research study, a 3D UE model (20), previously developed by our group, will be modified to incorporate ISB modeling standards and applied to a pediatric MM population.

Two types of gait patterns commonly used by children with MM were studied in this project. Reciprocal gait most closely resembles normal walking. The movement sequence for reciprocal gait is to progress the right crutch and left foot and then the left crutch and right foot. Swing-through gait is often used for walking quickly. The sequence occurs when one bears weight on the legs, then advances both crutches forward simultaneously, and then swings the body past the crutches. The movement of the legs is parallel and this type of gait requires considerable upper body strength to support the entire body weight. Another recognized gait pattern, but not studied in the current research project, is swing-to gait. This pattern is identical to swingthrough gait, except the subject swings to the crutches and not through them.

A quantitative model for the evaluation of UE dynamics in children with MM is essential. To build on our group's recent report of a validated UE kinematic model for adult rehabilitation (20), we propose a biomechanical assessment of UE dynamics during Lofstrand crutchassisted gait in children with MM. A pediatric model may be a valuable tool for clinicians to characterize crutch-assisted gait. The analysis is

The Journal of Spinal Cord Medicine, Vol. 30, Supplement 1 (2007): pg. S165-S171. Publisher Link. This article is (C) Maney Publishing and permission has been granted for this version to appear in e-Publications@Marquette. Maney Publishing does not grant permission for this article to be further copied/distributed or hosted elsewhere without the express permission from Maney Publishing. 
designed to identify the demands placed on the UE and the differences in UE movement during reciprocal and swing-through crutch-assisted gait in children with MM. The goal of our model is to detect alterations in kinematic patterns and includes the ability to detect limb asymmetry. We hypothesize that joint ranges of motion and axial crutch forces will be greater during swing-through gait than reciprocal gait. This study hopes to advance treatment monitoring, therapeutic planning, and crutch prescription. This study also has potential for improving clinical intervention strategies for children with MM.

\section{METHODS}

\section{Kinematic Model}

The UE model is composed of 7 rigid body segments: (a) thorax, (b) right upper arm, (c) right forearm, (d) right hand, (e) left upper arm, (f) left forearm, and ( $g$ ) left hand. A 3 degree-of-freedom shoulder (glenohumeral) joint, a 2 degree-of-freedom elbow joint, and a 2 degree-of-freedom wrist joint connect the segments. Varus and valgus is constrained at the elbow. Eighteen reflective markers $(9-\mathrm{mm}$ diameter) are placed on bony anatomical landmarks to define the body segments (Figure 1 and Table 1 ). Four markers are also placed on each Lofstrand crutch to determine its kinematics. The joint centers are calculated using subject specific anthropometric measurements, and for each segment embedded axes are defined. The thorax model and Euler angle sequence, based on research by Nguyen et al, is applied for clinical analysis of thorax kinematics in children with MM (14). The joint coordinate systems of the upper arm and forearm follow convention suggested by the ISB standards committee (21) Global wrist motion is determined by modeling the motion of the third metacarpal of the hand with respect to the forearm $(\underline{17}, \underline{21})$. Vicon BodyBuilder V3.6 (Vicon, Oxford, England) was used for the development of the model. The UE model has been previously evaluated for accuracy and precision (20). Rotations are described using Euler angles (Z-X-Y order). The rotations of the distal coordinate system are described with respect to the proximal coordinate system. The thorax and crutch segments are described with reference to the laboratory coordinate system. 
NOT THE PUBLISHED VERSION; this is the author's final, peer-reviewed manuscript. The published version may be accessed by following the link in the citation at the bottom of the page.

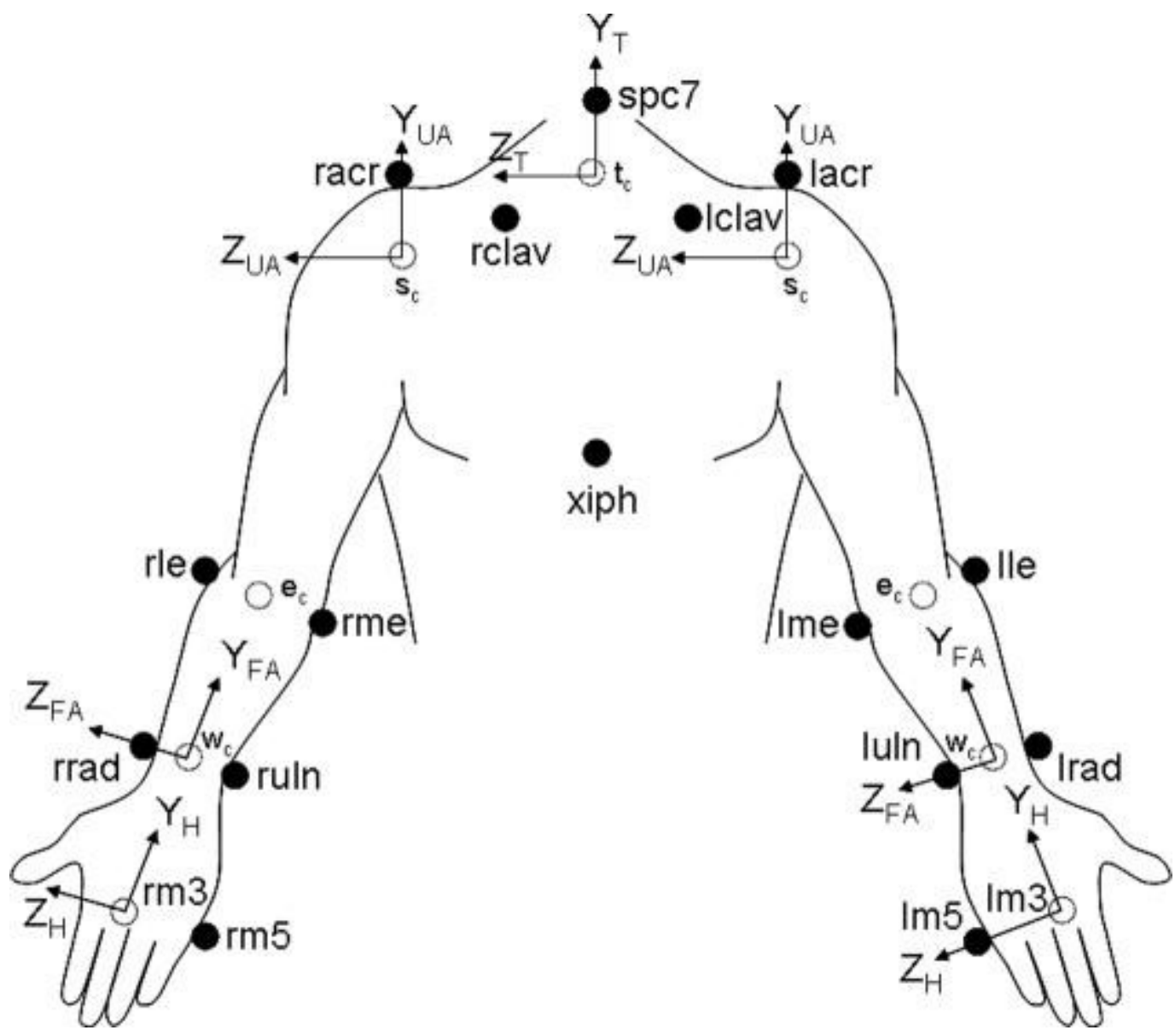

\section{Figure 1}

Upper extremity model. Joint coordinate systems for the thorax (T), upper arms (UA), forearms (FA), and hands (H). Markers are shown as black circles, and joint centers are shown as open circles.

\begin{tabular}{lll}
\hline Marker Name & \multicolumn{1}{c}{ Anatomical Landmark } & Body Segment \\
\hline spc7 & C7 vertebral process & Thorax \\
xiph & Xiphoid process & Thorax \\
r/lclav & L/R clavicles & Thorax \\
r/lacr & R/L acromion process & Upper arm \\
$\mathrm{r} / \mathrm{ll}$ & R/L lateral epicondyle & Upper arm and forearm \\
$\mathrm{r} / \mathrm{lme}$ & R/L medial epicondyle & Upper arm and forearm \\
$\mathrm{r} / \mathrm{luln}$ & R/L ulnar styloid & Forearm and hand \\
$\mathrm{r} / \mathrm{lrad}$ & R/L radial styloid & Forearm and hand \\
$\mathrm{r} / \mathrm{lm} 3$ & R/L third metacarpal (dorsal) & Hand \\
$\mathrm{r} / \mathrm{lm} 5$ & R/L fifth metacarpal (lateral) & Hand \\
\hline
\end{tabular}

Table 1 Marker Names, Anatomical Landmarks, and Corresponding Body Segments

The Journal of Spinal Cord Medicine, Vol. 30, Supplement 1 (2007): pg. S165-S171. Publisher Link. This article is (C) Maney Publishing and permission has been granted for this version to appear in e-Publications@Marquette. Maney Publishing does not grant permission for this article to be further copied/distributed or hosted elsewhere without the express permission from Maney Publishing. 


\section{Subjects}

Five subjects, aged $9.8 \pm 1.6$ years, were recruited and participated in the research study. Written parental consent and subject assent were obtained in compliance with IRB requirements. All subjects were recruited from Shriners Hospital in Chicago, Illinois. The subject population included 3 girls and 2 boys, ranging from age 8 to 12 years. All subjects had L3 or L4 level myelodysplasia and believed they were ambulatory using Lofstrand crutches in both reciprocal and swing-through gait patterns. One subject, however, was unable to perform swing-through gait as requested and performed swing-to gait. Another subject was receiving physical therapy once per week at school and once per week as an outpatient. Subjects who had undergone orthopedic surgery in the past year were excluded from the study.

\section{Instrumentation}

All subjects regularly used Walk Easy crutches, which were also used for the instrumented crutch (full-cuff) design. Lofstrand crutches (Walk Easy, Inc, Delray Beach, FL) were instrumented with MCW-6500 walker sensors (AMTI, Watertown, MA) to measure applied reaction forces along the $X, Y$, and $Z$ axes. The bodies of the load cells are manufactured from a high-strength aluminum alloy. Characteristics of the sensors include high stiffness, high sensitivity, low cross-talk ( $\leq 2 \%$ on all channels), excellent repeatability, and long-term stability. The sensors incorporate strain gages mounted on a strain element to measure forces. AMTI MSA- 6 high-gain amplifiers provide excitation and amplification of the transducers. Each sensor was calibrated by AMTI. The calibration procedure provides a detailed sensitivity matrix and a complete test of all system components.

Accuracy and precision of the right and left crutch sensors were determined by applying $17.79 \mathrm{~N}(4 \mathrm{lb})$ on the principal vertical axis and comparing the output from the sensors to the actual weight. The root mean square error was used to calculate each sensor's accuracy, while standard deviation was computed to evaluate precision. 


\section{Data Collection, Processing, and Analysis}

All patients were comfortable with the instrumented crutches prior to testing, which were similar to the ones usually used. Subjects walked with the instrumented bilateral Lofstrand crutches at a selfselected speed along a 6-meter walkway until 5 successful trials were completed for each gait pattern. Lower extremity bracing was not worn during motion analysis. A 14-camera Vicon MX motion analysis system captured the 3D motion of the reflective markers placed on the subject and crutches at $120 \mathrm{~Hz}$. Motion data were processed using Vicon Workstation V4.6 software to produce 3D coordinates of each marker. Further analysis was completed with Matlab (The MathWorks, Inc, Natick, MA). All data were averaged over 5 gait cycles and time normalized for right and left sides to $100 \%$ gait cycle. The data were processed for every $1 \%$ of the gait cycle.

Temporal-distance parameters, including cadence, walking speed, stride length, and stance duration, were computed. Cadence is defined as the number of steps per minute. A step occurs during stance duration of a limb (left or right). For the study, the average cadence for the left and right sides was reported. Stance duration (\%) occurs when a limb contacts the ground. This assessment is performed independently for each limb (left and right). The resulting reported stance duration is the average for the left and right limbs over the entire series of trials. These methods for assessment of temporal and stride parameters were applied to both reciprocal and swing-through gait patterns as described by Rose et al (22). Thorax, shoulder, elbow, and wrist ranges of motion in the sagittal plane (flexion/extension) were calculated during reciprocal and swing-through gait. Mean peak axial crutch forces were determined for reciprocal gait and swingthrough gait patterns. Quantification of peak force levels demonstrates the magnitude of demand that the UE joints (shoulder, elbow, and wrist) must counteract in order to preserve joint integrity and avoid injury (23). Temporal-distance parameters, joint ranges of motion, and peak forces were statistically analyzed by comparing reciprocal gait to swing-through gait using the nonparametric paired-sample Wilcoxon signed rank test with a level of significance of $P<0.1$. 
NOT THE PUBLISHED VERSION; this is the author's final, peer-reviewed manuscript. The published version may be accessed by following the link in the citation at the bottom of the page.

\section{RESULTS}

The Wilcoxon rank sum test revealed that swing-to gait was not significantly different from swing-through gait in temporal-distance parameters, UE ranges of motion, and crutch forces. As a result of these findings, the subject who performed swing-to gait was included in all analyses.

The mean walking speed, cadence, and stride length were greatest during swing-through gait (Table 2). Sagittal plane joint motion (flexion/extension) was calculated during reciprocal gait and swing-through gait for right (Figure 2) and left (Figure 3) UEs. Although the 2 gait patterns have differing pattern morphology, the thorax and elbows remained flexed throughout the gait cycles, while the wrists remained extended. For both gait cycles, the shoulders were in flexion from 0 to $5 \%$ of the gait cycle, then extension from 6 to $25 \%$ of the gait cycle, and then in flexion from 26 to $100 \%$. Reciprocal and swing-through gait patterns differ markedly in the joint ranges of motion. The ranges of motion of the thorax, shoulders, elbows, and wrists were greater for swing-through gait than reciprocal gait (Figure 4 ). The difference in thorax range of motion was significant $(P=$ 0.0625 ). The analysis of right vs left UE does not reflect any significant difference $(P<0.05)$ for either the reciprocal or swing-through gait pattern. However, if asymmetries become apparent as we increase the study population, the model is designed to detect them.

\begin{tabular}{lrc} 
Temporal Parameter & $\begin{array}{c}\text { Reciprocal } \\
\text { Gait }\end{array}$ & $\begin{array}{c}\text { Swing-Through } \\
\text { Gait }\end{array}$ \\
\hline Walking speed (m/s) & 0.39 & 0.59 \\
Cadence (steps/min) & 67.12 & 75.43 \\
Stride length (m) & 0.66 & 0.86 \\
Stance duration (\%) & 0.66 & 0.63
\end{tabular}

Table 2 Mean Temporal-Distance Parameters for Reciprocal and Swing-Through Gait

The Journal of Spinal Cord Medicine, Vol. 30, Supplement 1 (2007): pg. S165-S171. Publisher Link. This article is (C) Maney Publishing and permission has been granted for this version to appear in e-Publications@Marquette. Maney Publishing does not grant permission for this article to be further copied/distributed or hosted elsewhere without the express permission from Maney Publishing. 
NOT THE PUBLISHED VERSION; this is the author's final, peer-reviewed manuscript. The published version may be accessed by following the link in the citation at the bottom of the page.
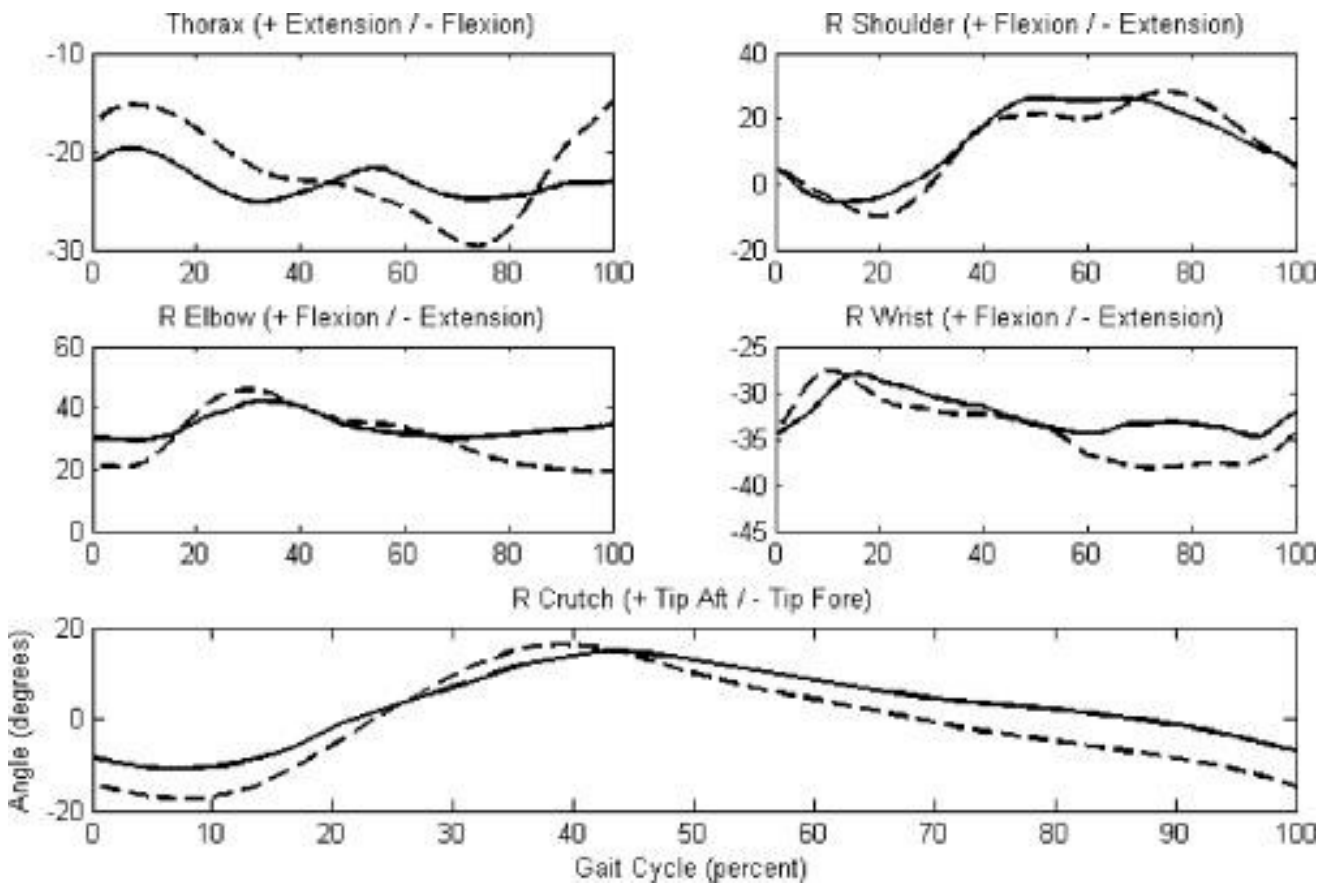

Figure 2 Mean reciprocal and swing-through gait motion patterns for the thorax, right shoulder, right elbow, right wrist, and right Lofstrand crutch. Sagittal plane kinematics of reciprocal gait (solid) and swing-through gait (dashed) are displayed.
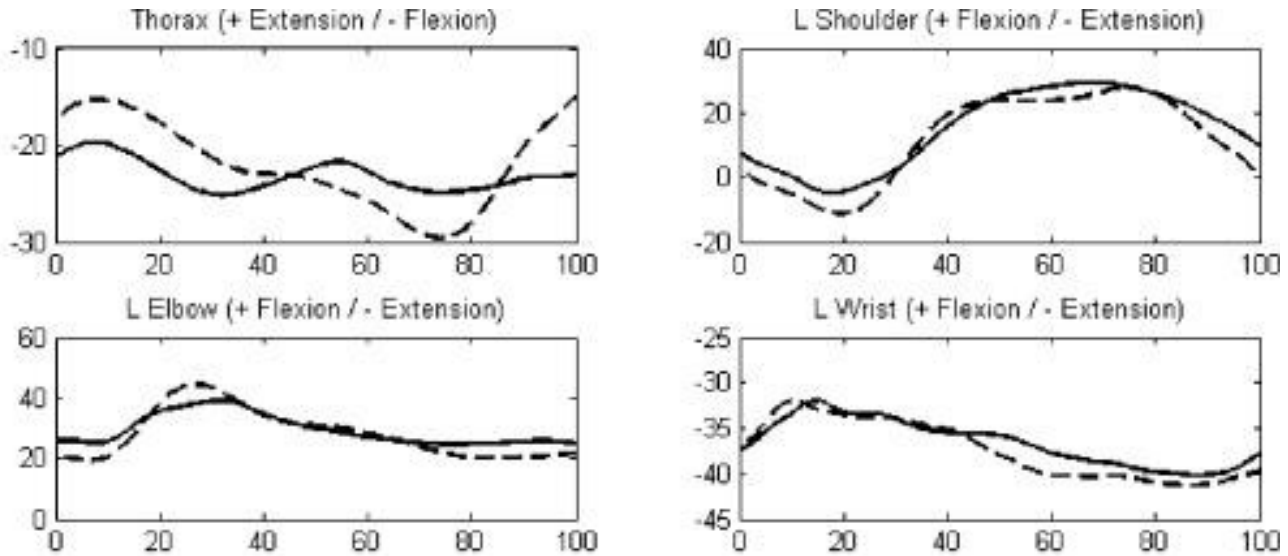

L Wrist (+ Flexion $/ \cdot$ Extension)

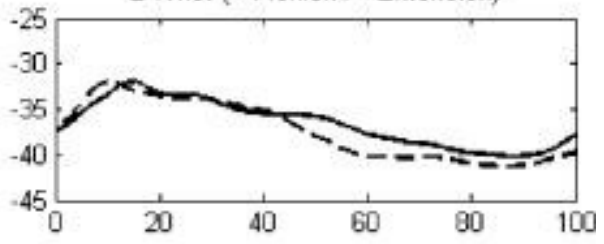

L Crutch (+ Tip Aft / - Tip Fore)

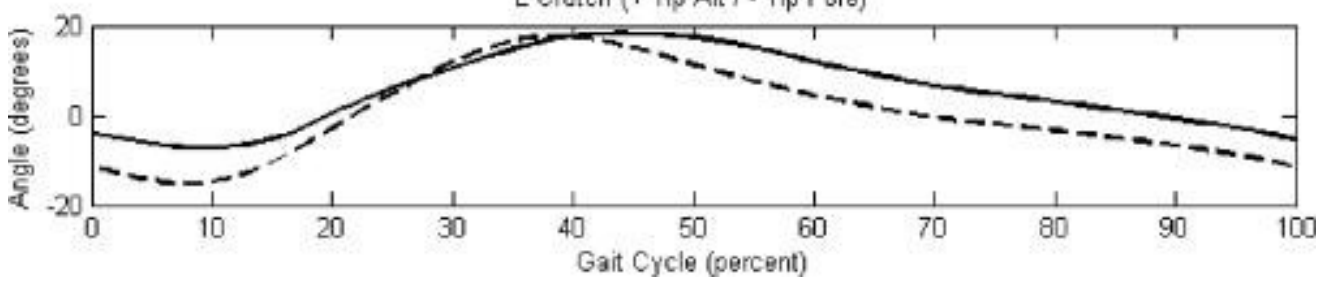

Figure 3 Mean reciprocal and swing-through gait motion patterns for the thorax, left shoulder, left elbow, left wrist, and left Lofstrand crutch. Sagittal plane kinematics of reciprocal gait (solid) and swing-through gait (dashed) are displayed.

The Journal of Spinal Cord Medicine, Vol. 30, Supplement 1 (2007): pg. S165-S171. Publisher Link. This article is (C) Maney Publishing and permission has been granted for this version to appear in e-Publications@Marquette. Maney Publishing does not grant permission for this article to be further copied/distributed or hosted elsewhere without the express permission from Maney Publishing. 
NOT THE PUBLISHED VERSION; this is the author's final, peer-reviewed manuscript. The published version may be accessed by following the link in the citation at the bottom of the page.

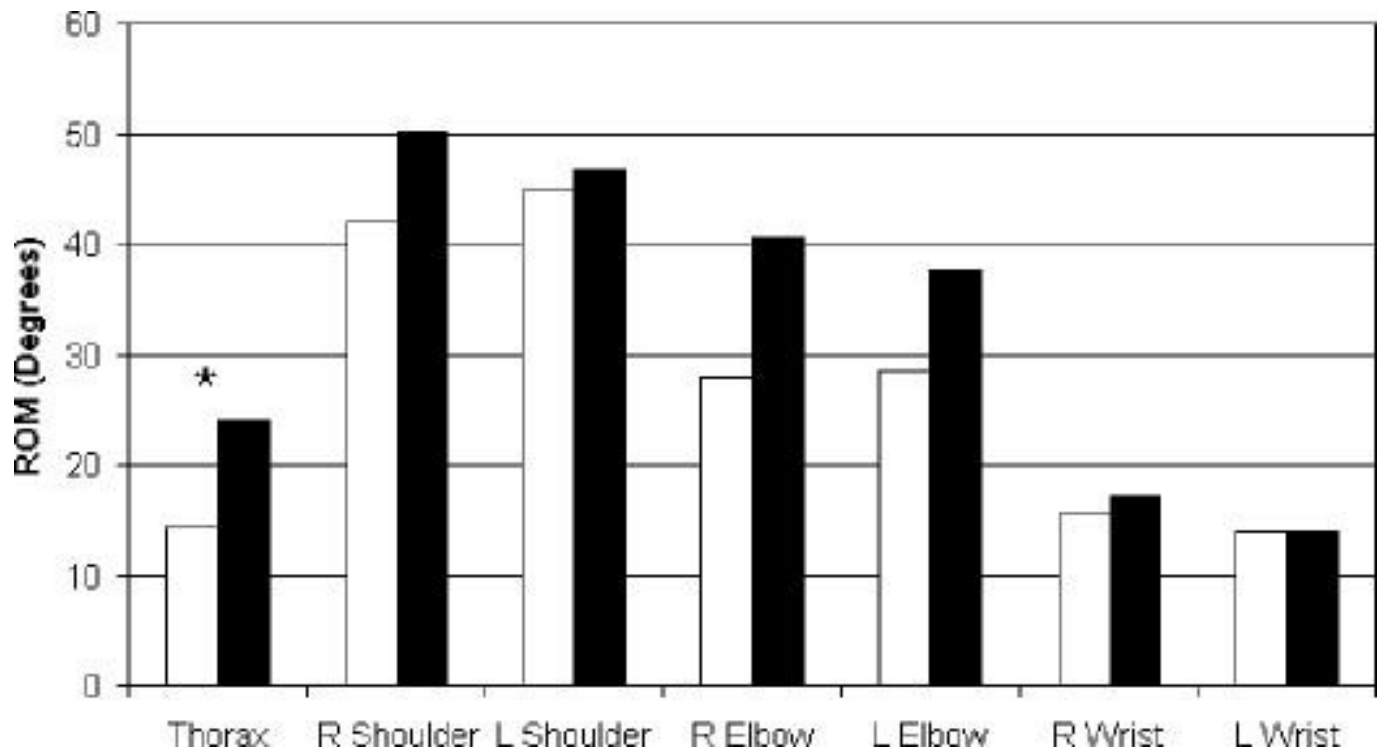

Figure 4 Mean range of motion (ROM) of the thorax, shoulders, elbows, and wrists during reciprocal (white) and swing-through (black) gait cycles. *Swing-through gait significantly greater than reciprocal gait $(P<0.1)$.

The root mean square error, which was used to evaluate each crutch sensor's accuracy, was found to be $2.61 \%$ for the right crutch and $3.27 \%$ for the left crutch (Table 3 ). The standard deviations, corresponding to accuracy, were similar for the right and left crutches, $0.74 \mathrm{~N}$ and $0.76 \mathrm{~N}$, respectively (Table 3).

\begin{tabular}{lcc}
\hline $\begin{array}{l}\text { Crutch } \\
\text { Sensor }\end{array}$ & $\begin{array}{c}\text { Root Mean Square } \\
\text { Error (\%) }\end{array}$ & $\begin{array}{c}\text { Standard } \\
\text { Deviation (N) }\end{array}$ \\
\hline Right & 2.61 & 0.74 \\
Left & 3.27 & 0.76 \\
\hline
\end{tabular}

Table 3 Evaluation of Right and Left Crutch Sensors

Mean peak axial crutch forces were calculated for right and left sides during reciprocal gait and swing-through gait (Figure 5). Forces were normalized to body weight. Mean peak axial forces for reciprocal gait were $45.10 \%$ body weight on the right and $44.75 \%$ body weight on the left, while swing-through gait forces were $57.18 \%$ body weight on the right and $55.62 \%$ body weight on the left. The forces in excess of body weight are consistent with dynamic motion patterns (24). The

The Journal of Spinal Cord Medicine, Vol. 30, Supplement 1 (2007): pg. S165-S171. Publisher Link. This article is (C) Maney Publishing and permission has been granted for this version to appear in e-Publications@Marquette. Maney Publishing does not grant permission for this article to be further copied/distributed or hosted elsewhere without the express permission from Maney Publishing. 
crutch forces were greater for both right and left sides during swingthrough gait than reciprocal gait. The mean peak forces in the right crutch were significantly greater $(P=0.0625)$ for swing-through gait than reciprocal gait.

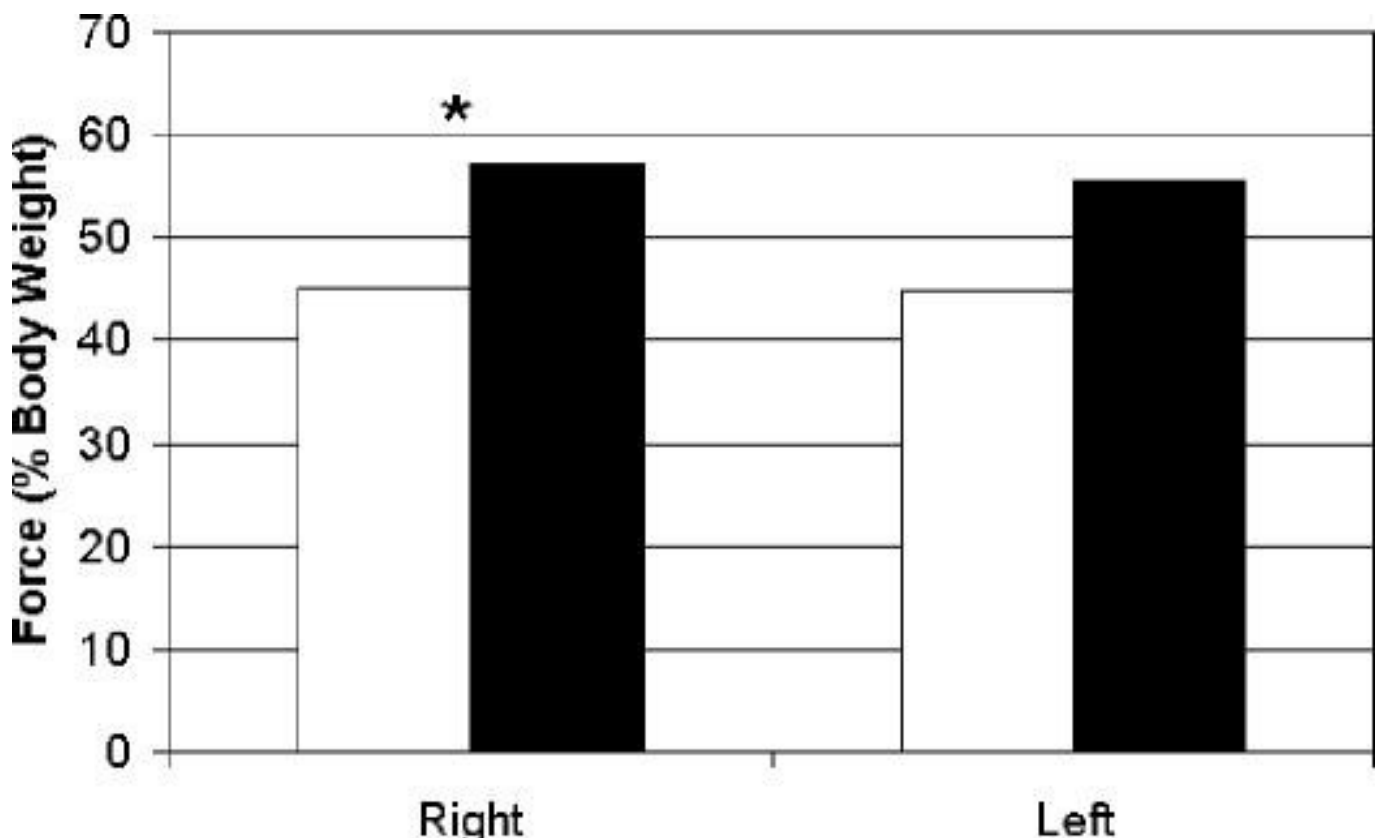

Figure 5 Mean peak axial crutch forces during reciprocal (white) and swing-through (black) gait cycles. Forces are normalized to body weight. *Swing-through gait significantly greater than reciprocal gait $(P<0.1)$.

\section{DISCUSSION}

A multisegment 3D biomechanical model of the UE is proposed. The thorax, shoulders, elbows, and wrists are described quantitatively. The UE dynamic model was successfully developed and evaluated. This model was uniquely designed for analysis of gait in children with MM and therefore applied to 5 subjects to identify differences between crutch-assisted gait patterns. One subject was unable to perform swing-through gait as requested and performed swing-to gait. Further analysis was completed to compare swing-to gait to swing-through gait, which revealed that swing-to gait was not significantly different from swing-through gait in temporal-distance parameters, UE joint ranges of motion, and crutch forces. As a result of these findings, the subject who performed swing-to gait was included in all analyses. It 
should be noted that statistical analyses were completed with a small sample size and may not persist with a larger sample size.

Upper extremity model details were based on our group's previous work (20), as well as models reported in the literature $(\underline{14}, \underline{17}, \underline{21})$. The thorax was modeled after Nguyen's methods of calculating thorax kinematics in children with MM (14). The coordinate system design for the shoulder, elbow, and wrist follows guidelines set forth by the standards committee of the ISB (21). Adherence to these guidelines should foster enhanced communication between researchers and clinicians.

Currently, no studies exist that quantify UE motion during crutch-assisted gait in children with MM. A related study by Requejo et al investigated UE dynamics during reciprocal gait in 1 adult subject with spinal cord injury (17). Although the population differs from our study, the ranges of motion results are similar. The peak axial forces exerted on the crutches ranged from 45 to $57 \%$ body weight. Vertical crutch forces ranging from 10 to $60 \%$ body weight have been reported $(\underline{16}, \underline{17}, \underline{25}, \underline{26})$. This may provide information regarding the joint demands and the potential for injury.

The UE dynamic model has been effectively developed and evaluated. This model was applied to 5 subjects for analysis of gait in children with MM. Analysis showed significant differences in thorax range of motion and right crutch peak axial forces between reciprocal and swing-through gait. Ranges of motion and crutch forces were found to be greatest during swing-through gait. This can be attributed to the large demands placed on the UE during swing-through gait. Additional insight may be gained from the study sample. Power analysis ( $80 \%$ power, $P=0.05$ ) indicates that 20 to 30 subjects will be needed to detect a significant difference between reciprocal and swingthrough gait range of motion (Trunk) and crutch forces. Significant differences may also be found in the shoulder, elbow, and wrist ranges of motion with larger sample populations.

The information gained in this study may be useful to develop an improved assessment protocol and to gain a better understanding of UE dynamics during Lofstrand crutch-assisted gait. Future work includes calculating joint kinetics, characterizing these dynamic 
patterns, and identifying correlations with standardized clinical and functional outcomes assessment tools, such as the Pediatrics Outcomes Data Collection Instrument and the Manual Muscle Test.

\section{CONCLUSIONS}

A 3D biomechanical model of the UEs was developed and applied to 5 children with MM for quantification of crutch-assisted gait. The model was used for analysis of reciprocal and swing-through gait. The model accurately tracks the joint angles of the thorax, shoulders, elbows, and wrists. Lofstrand crutches were instrumented with 6-axis load cells to obtain reaction force components. Unique design and careful evaluation of the UE model indicate it is appropriate for comparing UE motion and reaction forces during crutch-assisted gait in children with MM. It is hoped that the study findings will prove useful through advances in treatment monitoring, therapeutic planning, and crutch prescription.

\section{Acknowledgments}

This work is supported by the Orthopaedic and Rehabilitation Engineering Center and Shriners Hospitals for Children in Chicago, Illinois. The authors thank Mei Wang, Sahar Hassani, Adam Graf, Kathy Reiners, and Vicky Young for their contributions to this project.

\section{References}

1. Davis BE, Daley CM, Shurtleff DB, et al. Long-term survival of individuals with myelomeningocele. Pediatr Neurosurg. 2005;41(4):186-191.

2. Farley JA, Dunleavy MJ. Myelodysplasia. In: Jackson PL, Vessey JA, editors. Primary Care of the Child With a Chronic Condition. 4th ed. St Louis, MO: Mosby-Year Book Inc; 1996. pp. 630-643.

3. Centers for Disease Control and Prevention Improved national prevalence estimates for 18 selected major birth defects: United States, 19992001. MMWR Morb Mortal Wkly Rep. 2006;54(51):1301-1305.

4. Canfield MA, Honein MA, Yuskiv N, et al. National estimates and race/ethnic-specific variation of selected birth defects in the United States, 1999-2001. Birth Defects Research. Part A, Clinical and Molecular Teratology. 2006;76(11):747-756.

5. Kolaski K. Massagli TL, Talavera F, Kolaski K, Allen KL, Lorenzo CT, editors. Myelomeningocele. 2006. eMedicine from WebMD. Available

The Journal of Spinal Cord Medicine, Vol. 30, Supplement 1 (2007): pg. S165-S171. Publisher Link. This article is (C) Maney Publishing and permission has been granted for this version to appear in e-Publications@Marquette. Maney Publishing does not grant permission for this article to be further copied/distributed or hosted elsewhere without the express permission from Maney Publishing. 
at: http://www.emedicine.com/pmr/topic83.htm. Accessed September 20, 2006.

6. Schopler SA, Menelaus MB, Schopler SA, Menelaus MB. Significance of the strength of the quadriceps muscles in children with myelomeningocele. J Pediatr Orthop. 1987;7(5):507-512.

7. Bartonek A, Gutierrez EM, Haglund-Akerlind Y, Saraste H. The influence of spasticity in the lower limb muscles on gait pattern in children with sacral to mid-lumbar myelomeningocele: a gait analysis study. Gait Posture. 2005;22(1):10-25.

8. Gabrieli AP, Vankoski SJ, Dias LS, et al. Gait analysis in low lumbar myelomeningocele patients with unilateral hip dislocation or subluxation. J Pediatr Orthop. 2003;23(3):330-334.

9. Gutierrez EM, Bartonek A, Haglund-Akerlind $Y$, Saraste H. Characteristic gait kinematics in persons with lumbosacral myelomeningocele. Gait Posture. 2003;18(3):170-177.

10. Gutierrez EM, Bartonek A, Haglund-Akerlind Y, Saraste H. Kinetics of compensatory gait in persons with myelomeningocele. Gait Posture. $2005 ; 21(1): 12-23$.

11. Vankoski S, Moore C, Statler KD, Sarwark JF, Dias L. The influence of forearm crutches on pelvic and hip kinematics in children with myelomeningocele: don't throw away the crutches. Dev Med Child Neurol. 1997;39(9):614-619.

12. Bartonek A, Saraste H, Eriksson M, Knutson L, Cresswell AG. Upper body movement during walking in children with lumbosacral myelomeningocele. Gait Posture. 2002;15(2):120-129.

13. Gupta RT, Vankoski S, Novak RA, Dias LS. Trunk kinematics and the influence on valgus knee stress in persons with high sacral level myelomeningocele. J Pediatr Orthop. 2005;25(1):89-94.

14. Nguyen TC, Baker R. Two methods of calculating thorax kinematics in children with myelomeningocele. Clin Biomech. 2004;19(10):10601065.

15. Moore CA, Nejad B, Novak RA, Dias LS. Energy cost of walking in low lumbar myelomeningocele. J Pediatr Orthop. 2001;21(3):388-391.

16. Melis EH, Torres-Moreno R, Barbeau H, Lemaire ED. Analysis of assistedgait characteristics in persons with incomplete spinal cord injury. Spinal Cord. 1999;37(6):430-439.

17. Requejo PS, Wahl DP, Bontrager EL, et al. Upper extremity kinetics during Lofstrand crutch-assisted gait. Med Eng Phys. 2005;27(1):19-29.

18. Bachschmidt RA, Harris GF, Simoneau GG. Walker-assisted gait in rehabilitation: a study of biomechanics and instrumentation. IEEE Trans Rehabil Eng. 2001;9(1):96-105.

19. Rab G, Petuskey K, Bagley A. A method for determination of upper extremity kinematics. Gait Posture. 2002;15(2):113-119. 
NOT THE PUBLISHED VERSION; this is the author's final, peer-reviewed manuscript. The published version may be accessed by following the link in the citation at the bottom of the page.

20. Hingtgen B, McGuire JR, Wang M, Harris GF. An upper extremity kinematic model for evaluation of hemiparetic stroke. J Biomech.

2006;39(4):681-688.

21. Wu G, van der Helm FC, Veeger HE, et al. ISB recommendation on definitions of joint coordinate systems of various joints for the reporting of human joint motion. Part II: shoulder, elbow, wrist and hand. J Biomech. 2005;38(5):981-992.

22. Rose J, Gamble JG. Human Walking. 3rd ed. Philadelphia, PA: Lippincott Williams \& Wilkins; 2006.

23. Haubert LL, Gutierrez DD, Newsam CJ, Gronley JK, Mulroy SJ, Perry J. A comparison of shoulder joint forces during ambulation with crutches versus a walker in persons with incomplete spinal cord injury. Arch Phys Med Rehabil. 2006;87:63-70.

24. Winter DA. Biomechanics and Motor Control of Human Movement. 3rd ed. Hoboken, NJ: John Wiley \& Sons, Inc; 2005.

25. Opila KA, Nicol AC, Paul JP. Forces and impulses during aided gait. Arch Phys Med Rehabil. 1987;68(10):715-722.

26. Youdas JW, Kotajarvi BJ, Padgett DJ, Kaufman KR. Partial weight-bearing gait using conventional assistive devices. Arch Phys Med Rehabil. 2005;86(3):394-398.

The Journal of Spinal Cord Medicine, Vol. 30, Supplement 1 (2007): pg. S165-S171. Publisher Link. This article is (C) Maney Publishing and permission has been granted for this version to appear in e-Publications@Marquette. Maney Publishing does not grant permission for this article to be further copied/distributed or hosted elsewhere without the express permission from Maney Publishing. 